\title{
Reliability and validity of pressure and temporal parameters recorded using a pressure-sensitive insole during running.
}

Citation for published version (APA):

Mann, R. M., Malisoux, L., Brunner, R., Gette, P., Urhausen, A., Statham, A., Meijer, K., \& Theisen, D. (2014). Reliability and validity of pressure and temporal parameters recorded using a pressure-sensitive insole during running. Gait \& Posture, 39(1), 455-459. https://doi.org/10.1016/j.gaitpost.2013.08.026

Document status and date:

Published: 01/01/2014

DOI:

10.1016/j.gaitpost.2013.08.026

Document Version:

Publisher's PDF, also known as Version of record

\section{Document license:}

Taverne

Please check the document version of this publication:

- A submitted manuscript is the version of the article upon submission and before peer-review. There can be important differences between the submitted version and the official published version of record.

People interested in the research are advised to contact the author for the final version of the publication, or visit the DOI to the publisher's website.

- The final author version and the galley proof are versions of the publication after peer review.

- The final published version features the final layout of the paper including the volume, issue and page numbers.

Link to publication

\footnotetext{
General rights rights.

- You may freely distribute the URL identifying the publication in the public portal. please follow below link for the End User Agreement:

www.umlib.nl/taverne-license

Take down policy

If you believe that this document breaches copyright please contact us at:

repository@maastrichtuniversity.nl

providing details and we will investigate your claim.
}

Copyright and moral rights for the publications made accessible in the public portal are retained by the authors and/or other copyright owners and it is a condition of accessing publications that users recognise and abide by the legal requirements associated with these

- Users may download and print one copy of any publication from the public portal for the purpose of private study or research.

- You may not further distribute the material or use it for any profit-making activity or commercial gain

If the publication is distributed under the terms of Article $25 \mathrm{fa}$ of the Dutch Copyright Act, indicated by the "Taverne" license above, 


\title{
Reliability and validity of pressure and temporal parameters recorded using a pressure-sensitive insole during running
}

\author{
Robert Mann ${ }^{\mathrm{a}, \mathrm{b}}$, Laurent Malisoux ${ }^{\mathrm{a}}$, Roman Brunner ${ }^{\mathrm{a}}$, Paul Gette ${ }^{\mathrm{a}}$, Axel Urhausen ${ }^{\mathrm{a}, \mathrm{c}}$, \\ Andrew Statham ${ }^{\mathrm{d}}$, Kenneth Meijer ${ }^{\mathrm{b}}$, Daniel Theisen ${ }^{\mathrm{a}, *}$ \\ ${ }^{a}$ Sports Medicine Research Laboratory, Public Research Centre for Health, 76 rue d'Eich, L-1460 Luxembourg, Luxembourg \\ ${ }^{\mathrm{b}}$ NUTRIM School for Nutrition, Toxicology and Metabolism, Maastricht University, Universiteitssingel 40, 6229 ER Maastricht, The Netherlands \\ ' Sports Clinic, Centre Hospitalier de Luxembourg, 78 rue d'Eich, L-1460 Luxembourg, Luxembourg \\ ${ }^{\mathrm{d}}$ TNO, Eindhoven, De Rondom 1, 5612 AP Eindhoven, The Netherlands
}

\section{A R T I C L E I N F O}

Article history:

Received 20 February 2013

Received in revised form 2 August 2013

Accepted 25 August 2013

\section{Keywords:}

Strike index

Foot strike pattern

Biomechanics

\begin{abstract}
A B S T R A C T
Running biomechanics has received increasing interest in recent literature on running-related injuries, calling for new, portable methods for large-scale measurements. Our aims were to define running strike pattern based on output of a new pressure-sensitive measurement device, the Runalyser, and to test its validity regarding temporal parameters describing running gait. Furthermore, reliability of the Runalyser measurements was evaluated, as well as its ability to discriminate different running styles. Thirty-one healthy participants ( $30.3 \pm 7.4$ years, $1.78 \pm 0.10 \mathrm{~m}$ and $74.1 \pm 12.1 \mathrm{~kg}$ ) were involved in the different study parts. Eleven participants were instructed to use a rearfoot (RFS), midfoot (MFS) and forefoot (FFS) strike pattern while running on a treadmill. Strike pattern was subsequently defined using a linear regression $\left(R^{2}=0.89\right)$ between foot strike angle, as determined by motion analysis $(1000 \mathrm{~Hz})$, and strike index (SI, point of contact on the foot sole, as a percentage of foot sole length), as measured by the Runalyser. MFS was defined by the $95 \%$ confidence interval of the intercept $(S I=43.9-49.1 \%$ ). High agreement (overall mean difference $1.2 \%$ ) was found between stance time, flight time, stride time and duty factor as determined by the Runalyser and a force-measuring treadmill ( $n=16$ participants). Measurements of the two devices were highly correlated $(R \geq 0.80)$ and not significantly different. Test-retest intra-class correlation coefficients for all parameters were $\geq 0.94$ ( $n=14$ participants). Significant differences $(p<0.05)$ between FFS, RFS and habitual running were detected regarding SI, stance time and stride time ( $n=24$ participants). The Runalyser is suitable for, and easily applicable in large-scale studies on running biomechanics.
\end{abstract}

(c) 2013 Elsevier B.V. All rights reserved.

\section{Introduction}

Biomechanics of human running has recently received new interest within the area of running-related injuries [1]. One aspect which is being rigorously discussed is the role of foot strike pattern in injury incidence [1-4]. It has been suggested that a forefoot strike (FFS) running pattern could have a protective effect against certain running-related injuries, through greater leg compliance upon foot contact with the ground, reduced stride length and thereby reduced vertical loading rate [1]. Another study [5] attributed a shorter stance time ( $\left.T_{\text {stance }}\right)$ and increased step frequency to FFS running compared to a rear-foot strike (RFS), highlighting the relevance of evaluating both temporal parameters and foot strike pattern when studying risk factors of injuries.

\footnotetext{
* Corresponding author at: Sports Medicine Research Laboratory, Centre de Recherche Publique de la Santé, 76 rue d'Eich, L-1460 Luxembourg, Luxembourg. Tel.: +352 26917824

E-mail address: daniel.theisen@crp-sante.lu (D. Theisen).
}

Foot strike pattern has previously been quantified by using strike index (SI) as a measure [6,7]. SI is defined as the point of contact on the foot sole with the running surface, expressed as a percentage of total sole length [6]. Previous studies [6,7] divided the foot sole into equal thirds to represent RFS, mid-foot strike (MFS) and FFS patterns, respectively. However, on no occasion has SI been compared to the actual foot strike angle (FSA) to determine a representative classification of foot strike pattern.

Temporal parameters are typically studied using motion analysis systems, force plates and pressure mats. Runners are therefore rarely tested in their habitual setting and required to perform several trials along a runway $[8,9]$. These measured steps are subject to high variability, can be time consuming to acquire and analyse [10], and may perhaps not always yield representative data of the participant's true running style. Treadmills with built-in force plates solve the problem of multiple trials, but are costly and therefore rarely available in a clinical setting.

An alternative method, one which overcomes the drawback of isolating steps and confining testing to the laboratory, is to use a pressure sensitive insole. The Runalyser by TNO (Eindhoven, The 
Netherlands), as the name suggests, comprises such an insole developed specifically to analyse pressure patterns and temporal parameters at the foot-ground contact during running. However, this system is at the prototype stage of development, and needs to be tested for validity and reliability. Therefore, the aims of this study were four-fold. Firstly, to devise a valid definition of strike pattern by comparing the SI using the Runalyser to the actual FSA. Secondly, to validate temporal parameters by comparing Runalyser data to that acquired using an instrumented treadmill measuring ground reaction forces. The third aim was to test the reliability of the output of the Runalyser using a test-retest approach. Additionally, a descriptive analysis of variables measured using the Runalyser for different foot strike patterns is provided.

\section{Methods}

\subsection{Participants}

A total of 31 participants ( 24 male and 7 female) were recruited. Mean \pm SD age, height and weight were $30.3 \pm 7.4$ years, $1.78 \pm 0.10 \mathrm{~m}$ and $74.1 \pm 12.1 \mathrm{~kg}$, respectively. Subsets of this initial sample constituted the cohorts of the individual study parts. They were all free of injury at the time of testing, were accustomed to running on a treadmill and provided written informed consent prior to inclusion. This research was approved by the National Research Ethics Committee.

\subsection{The Runalyser}

Participants were equipped with the Runalyser consisting of an insole ( $3 \mathrm{~mm}$ thick) and a microprocessor clipped to the lateral aspect of the shoe. The microprocessor acquires and transmits realtime pressure data wirelessly to a nearby computer at a rate of $247 \mathrm{~Hz}$ for the left and right foot separately. The insole comprises eight capacitive sensors [11] distributed as follows: medial heel, lateral heel, medial mid-foot, lateral mid-foot, first metatarsal head, second metatarsal head, fourth metatarsal head and the hallux [12]. Insoles are available in small, medium and large sizes. They were positioned on top of the original running shoe insole, thus ensuring direct contact with the foot. Due to the dimensions of the pressure sensors, the insole has a SI sensitive zone between $12.5 \%$ at the heel and $86.3 \%$ at the toe (see Fig. 1 ). In knowing the distances of the sensors relative to each other and to the centre of

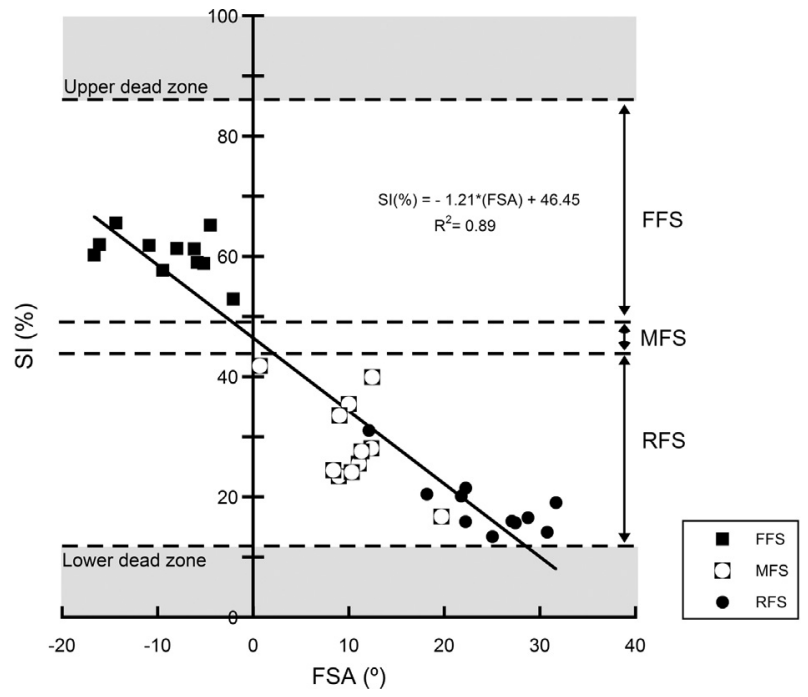

Fig. 1. A linear regression model depicting the correlation between SI and FSA for the three different running conditions ( $n=11$ participants). the insole, the centre of pressure location, and thus the SI can be calculated. Temporal parameters were established based on the curve representing the sum of all sensors and its first-grade derivative. Foot contact was defined as the time point when the first-grade derivative diverged from the zeroline, while the original curve remained below a certain threshold. Toe-off was determined by the time point when the first-grade derivative converged from a negative value towards the zeroline, with the original curve below a certain threshold. The thresholds for foot contact and toe-off were defined based on preliminary testing. $T_{\text {stance }}$ was taken as the time between foot contact and toe-off for each step, stride time $\left(T_{\text {stride }}\right)$ was the time from one foot contact to the next for the same foot, and flight time ( $\left.T_{\text {flight }}\right)$ the difference between $T_{\text {stride }}$ and $T_{\text {stance. }}$ The duty factor (DF) was obtained by dividing $T_{\text {stance }}$ by $T_{\text {stride }}$. Runalyser data were filtered using a 4 th order, lowpass Butterworth filter. The cut-off frequency varied between 49 and $51 \mathrm{~Hz}$ depending on the insole specific noise frequency determined for each individual acquisition based on a Fast-Fourier Transform. All Runalyser recordings lasted for a minimum of $30 \mathrm{~s}$ and were done simultaneously with other measurement devices (see below) to analyse the exact same running strides.

\subsection{SI validation}

Eleven participants took part in the SI validation study by running on a treadmill (Woodway PPS55 med I, USA) at a $0^{\circ}$ slope and a mean self-selected running speed of $3.03 \pm 1.04 \mathrm{~m} / \mathrm{s}$ (range $2.78-3.33 \mathrm{~m} / \mathrm{s}$ ). A motion analysis system (CODAmotion, Charnwood Dynamics, UK) was used to calculate the FSA of the sole of the running shoe with the surface of the treadmill. All tests were performed using a single shoe model of appropriate size, equipped with markers at the most posterior aspect of the calcaneus and the 1 st and 5th metatarsophalangeal joint. The marker at the calcaneus and a virtual marker midway between the 1 st and 5 th metatarsophalangeal joint markers constituted the foot reference line. Three further markers were placed on the treadmill, at the same height as the running surface, to provide the ground reference plane. Marker positions were acquired at $1000 \mathrm{~Hz}$ using three CX1 cameras placed at the front and either side of the treadmill. FSA was determined at foot contact, as derived from the Runalyser data which were synchronised with the kinematic recordings. FSA was defined as the difference between the 3D angle of the foot reference line at foot contact and the 3D angle determined during a static, standing acquisition for each participant. A positive FSA-value signified a RFS, and a negative value a FFS. After a 2-min warm-up, the participants were instructed to adopt a FFS, MFS and RFS pattern successively, each for approximately $2 \mathrm{~min}$. A FFS was described to them as making initial contact with the ground with the front portion of the foot or the toes; a MFS was described as landing with the sole of the foot parallel to the treadmill surface (heel and ball of the foot contacting the running surface simultaneously); a RFS was described as the heel of the foot making initial contact with the ground, and the foot subsequently rolling forward towards toe-off [1,13-15]. Data acquisition took place after the first minute to ensure that the requested running style was understood and fully adopted. Data were also acquired during the initial warm-up phase, without the participants' knowledge, so as to evaluate their habitual running style for subsequent classification. An average of $42 \pm 5$ steps were recorded per trial. Only data of the right foot were used for analysis of this study part.

\subsection{Temporal parameter validation}

Sixteen participants were included in the validation study of temporal parameters of the Runalyser. They ran at a self-selected running speed of $3.19 \pm 0.25 \mathrm{~m} / \mathrm{s}$ (range $2.79-3.33 \mathrm{~m} / \mathrm{s}$ ) in the same conditions as for the previous study part. This was done on a treadmill 
(Mercury LT med, HP Cosmos, Germany) instrumented with four 3D strain-gauge force transducers measuring ground reaction forces. The instrumented treadmill has been previously validated [16]. The strain gauges were calibrated prior to testing. Ground reaction forces were acquired at $1000 \mathrm{~Hz}$, and the data were filtered using a 4th order, lowpass Butterworth filter at $50.05 \mathrm{~Hz}$. A similar algorithm as described above for the Runalyser was used to detect foot contact and toe-off, and all temporal parameters were calculated in exactly the same manner. For each participant, an average of $76 \pm 13$ steps recorded during the habitual running condition was used to compare the two instruments. Left or right foot data were randomly selected for each participant.

\subsection{Runalyser reliability}

To test the reliability of the SI and temporal parameters as measured using the Runalyser, 14 participants ran on a treadmill (Woodway XELG 90, USA) using their habitual running style on two separate occasions (at least $24 \mathrm{~h}$ apart), under exactly the same conditions. The mean self-selected running speed was $2.5 \pm 0.5 \mathrm{~m} / \mathrm{s}$, and an average of $73 \pm 15$ steps per participant per foot were recorded. Left or right foot data were randomly selected for each participant for the analysis.

\subsection{Data analyses and statistics}

To compare the SI with FSA and devise a classification of running strike pattern according to SI, a least squares linear regression with SI as the dependent variable was performed. The upper and lower boundaries of the $95 \%$ confidence interval $(95 \% \mathrm{CI})$ of the $y$-intercept was used to determine the MFS condition. Temporal parameters as measured by the Runalyser and instrumented treadmill were analysed using Bland-Altman plots [17], correlations and paired sample $T$-tests. Reliability was tested by performing a one-way repeated measures analysis of variance (one-way RM ANOVA) on the test-retest data of the habitual running condition. From this we calculated the intra-class correlation coefficient (ICC) and minimal detectible change (MDC) for SI and temporal parameters data using the standard error of the measurement (SEM) [18]: $\mathrm{MDC}=1.96 \times \mathrm{SEM} \times \sqrt{ } 2$. Finally, Runalyser data of all variables collected for 24 participants having performed a RFS, FFS and habitual running were compared using a one-way RM ANOVA with the post hoc Bonferroni correction. Custom-built programmes in MATLAB (Mathworks Inc., USA) were used for data treatment, and all statistical analyses were performed using SPSS for Windows version 20. Statistical significance was accepted as $p<0.05$.
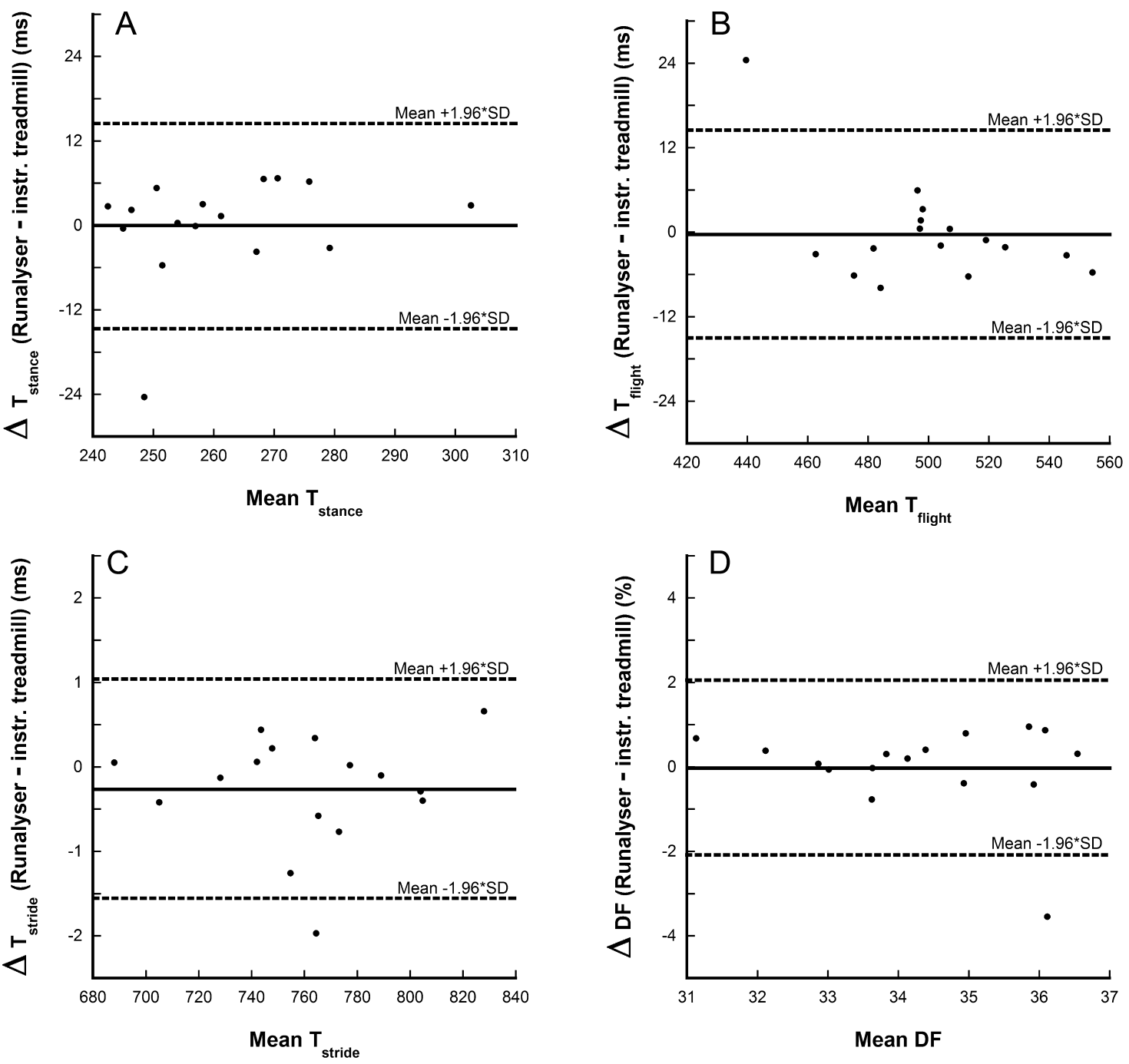

Fig. 2. Bland Altman plots for stance time (A), stride time (B), cycle time (C) and duty factor (D). $n=16$ participants. 
Table 1

Reliability of variables measured using the Runalyser (test-retest design, $n=14$ participants).

\begin{tabular}{|c|c|c|c|c|c|}
\hline & SI (\%) & $T_{\text {stance }}(\mathrm{ms})$ & $T_{\text {flight }}$ (ms) & $T_{\text {stride }}(\mathrm{ms})$ & $\mathrm{DF}(\%)$ \\
\hline Mean $( \pm \mathrm{SD})_{\text {Test }}$ & $25.0( \pm 10.5)$ & $295( \pm 36)$ & $490( \pm 46)$ & $785( \pm 54)$ & $37.6( \pm 4.0)$ \\
\hline Mean $( \pm \text { SD })_{\text {Retest }}$ & $25.2( \pm 10.5)$ & $298( \pm 37)$ & $485( \pm 50)$ & $783( \pm 54)$ & $38.1( \pm 4.3)$ \\
\hline$R^{2}$ & 0.94 & 0.95 & 0.89 & 0.96 & 0.89 \\
\hline ICC & 0.97 & 0.97 & 0.95 & 0.97 & 0.94 \\
\hline MDC & 4.9 & 16.4 & 29.2 & 24.5 & 2.7 \\
\hline
\end{tabular}

\section{Results}

SI values across the different running styles analysed in the first study part ranged between $13.4 \%$ and $65.6 \%$, while FSA ranged between $31.7^{\circ}$ and $-16.6^{\circ}$ (Fig. 1 ). The two variables had a strong $\left(R^{2}=0.89\right)$ linear relationship. The dashed lines in Fig. 1 illustrate the theoretical boundaries of the different foot strike pattern classifications represented by our approach. The SI window for a MFS (the $95 \% \mathrm{CI}$ of the intercept of the SI-FSA relationship) running condition was calculated as $[43.9,49.1]$. SI values above $49.1 \%$ were taken to be FFS, and values below $43.9 \%$ to be RFS. According to our definition, none of the participants adopted a true MFS, even when instructed to do so.

Fig. 2 depicts Bland-Altman plots of temporal parameters for habitual running as measured using the instrumented treadmill and Runalyser. Overall, the results of the two measuring devices showed no systematic error and narrow limits of agreement, representing $11.2 \%, 5.9 \%, 0.3 \%$ and $12.1 \%$ of the overall mean of both systems for $T_{\text {stance, }} T_{\text {flight }}, T_{\text {stride }}$ and DF, respectively. In addition, temporal parameters measured by the two devices were not significantly different and were highly correlated $(0.90,0.98$, 0.99 and 0.80 , respectively).

The results of the reliability testing of all Runalyser variables are presented in Table 1. The ICCs for all five variables were high, ranging from 0.94 to 0.97 . SI yielded a MDC of $4.9 \%$, whereas for temporal parameters it ranged from $16.4 \mathrm{~ms}$ ( $\left.T_{\text {stance }}\right)$ to $29.2 \mathrm{~ms}$ ( $\left.T_{\text {flight }}\right)$.

A descriptive analysis of the different running styles is summarised in Table 2. The SI obtained during habitual running revealed that all participants were RFS runners according to our definition. SI, $T_{\text {stance }}$ and $T_{\text {stride }}$ displayed overall significant differences between running styles. This was not the case for $T_{\text {flight }}$ and DF, for which effect size was low. RFS and habitual running were not significantly different. FFS yielded a significantly higher SI compared to both RFS and habitual running, while $T_{\text {stance }}$ was significantly lower than the two other styles. $T_{\text {stride }}$ was significantly lower in FFS compared to RFS.

\section{Discussion}

The Runalyser was found to be a valid and reliable instrument to assess foot strike pattern and temporal parameters during running, based on foot sole pressure measurements. We propose SI as a continuous scale of measurement and provide a classification reference of foot strike pattern validated against actual FSA measurements. This classification builds on earlier work by Cavanagh and Lafortune [6] who divided the foot into three sections of equal length, respectively defining a RFS, MFS and FFS. Although a clear-cut definition, it is arbitrarily determined and may lack precision in the study of different running strike patterns. On the other hand, classifications based on video analyses can be used on a large scale, but are less accurate and may overestimate the proportion of MFS runners [13,14]. Indeed, our approach suggests that there is only a very small SI window (between 43.9 and $49.1 \%$ ) for MFS when taking a $0^{\circ}$ FSA as the definition of this strike pattern. This narrow margin can be explained by the fact that there is only one way in which the foot can contact the ground in a true MFS condition (heel and ball of the foot striking the ground simultaneously), while there are many variations possible when using a FFS or RFS pattern [13]. In addition, when instructed to use a MFS, none of our participants achieved a true MFS according to our SI definition, with some even reporting discomfort. Using the SI as a continuous measure has the advantage of allowing a more indepth analysis of running strike pattern, independently of the classification used.

Analysis of the Bland-Altman plots reveals that there is good agreement between Runalyser and instrumented treadmill data for temporal parameters (Fig. 2). On average the difference between the two measurement systems was consistently close to zero. Limits of agreement for $T_{\text {stride }}$ (Fig. 2C) were $<3 \mathrm{~ms}$ apart, implying that the Runalyser is extremely accurate when detecting the initial contact point of each step. Limits of agreement for $T_{\text {stance }}$ (Fig. 2A) and $T_{\text {flight }}$ (Fig. 2B) were larger (29 and $30 \mathrm{~ms}$, respectively) illustrating somewhat less accuracy of the Runalyser in detecting the moment of toe-off. This is also reflected in the DF (Fig. 2D) where limits of agreement were $4.2 \%$ apart. A previous study comparing pressure insole data to force plate data during walking found overall mean differences of $1.8 \%$ for temporal parameters [19], which is comparable to our findings of $\sim 1.2 \%$.

Runalyser measurements were found to be highly reproducible. The MDCs reported describe a difference in Runalyser measurements that can be considered a true change, for example when comparing two groups of runners or when learning to adopt a different running style. A MDC of $4.9 \%$ for SI allows researchers to detect changes in running strike pattern within and between running style classifications.

As demonstrated by the results in Table 2, the Runalyser was able to discriminate different running styles. SI is a clear indicator of running strike pattern, as highlighted by the significant differences between FFS, RFS and habitual running. Our data

Table 2

Mean $( \pm \mathrm{SD})$ of variables measured using the Runalyser in the different running conditions ( $n=24$ participants).

\begin{tabular}{|c|c|c|c|c|c|c|}
\hline & HABIT & FFS & RFS & $p$-Value & Power & Effect size \\
\hline SI (\%) & $19.68( \pm 6.19)^{*}$ & $57.57( \pm 6.09)$ & $17.83( \pm 4.07)^{*}$ & $\leq 0.001$ & 1.000 & 0.952 \\
\hline$T_{\text {stance }}(\mathrm{ms})$ & $263( \pm 27)^{*}$ & $255( \pm 23)$ & $267( \pm 29)^{*}$ & 0.002 & 0.911 & 0.27 \\
\hline$T_{\text {flight }}(\mathrm{ms})$ & $485( \pm 33)$ & $478( \pm 44)$ & $487( \pm 41)$ & 0.310 & 0.250 & 0.05 \\
\hline$T_{\text {stride }}(\mathrm{ms})$ & $748( \pm 43)$ & $733( \pm 51)$ & $753( \pm 50)^{*}$ & 0.017 & 0.740 & 0.16 \\
\hline DF $(\%)$ & $35.21( \pm 2.55)$ & $34.83( \pm 2.55)$ & $35.47( \pm 2.79)$ & 0.109 & 0.447 & 0.09 \\
\hline
\end{tabular}

Significantly different to FFS; HABIT: habitual running style. 
suggest that when shifting from a RFS to a FFS, a runner is likely to shorten $T_{\text {stride }}$ by decreasing $T_{\text {stance, }}$, while keeping $T_{\text {flight }}$ more or less constant. These observations are consistent with a previous investigation showing that $T_{\text {stance, but not }} T_{\text {flight }}$, was significantly shorter during barefoot compared to shod running, the former inducing greater ankle plantar flexion at foot contact [20]. Another study [21] found that $T_{\text {stance }}$ was significantly reduced after six weeks of FFS running training in individuals with exertional compartment syndrome. In line with this, Hasegawa et al. [14] found that elite long-distance runners adopting a FFS displayed shorter $T_{\text {stance }}$ than their RFS counterparts.

Some limitations need to be considered when using the Runalyser. The number of sensors within the insole is limited. An increased number would provide a higher spatial resolution and could result in greater precision when determining the centre of pressure location. In the present context, however, the Runalyser provides sufficient accuracy for the concerned variables and has the advantage of remaining highly portable. The sensors are positioned directly beneath prominent anatomical structures of the foot, but no sensor is present at the 2 nd to 5 th phalanges. Slight variations in $T_{\text {stance }}$ and $T_{\text {flight }}$, as observed in Fig. 2, may be attributed to this. Of particular interest in this respect, are the results of a lightweight participant $(47.5 \mathrm{~kg})$ for whom $T_{\text {stance }}$ and $T_{\text {flight }}$ were under- and overestimated, respectively. This suggests that our algorithm to detect toe-off is slightly less accurate for very lightweight runners. However, this does not affect $T_{\text {stride }}$ or SI measurements.

To conclude, this study provides a reference to classify different running styles and suggests SI as a continuous measurement when using the Runalyser. Our results demonstrate that the device is valid and reliable when measuring temporal parameters. A main advantage is its ability to record large numbers of consecutive steps, needed to achieve representative data on running style [10,22]. The Runalyser was designed for overground (as well as outdoor) use, meaning a treadmill is not necessary for continuous measurement. Its portability and ease of application make it an interesting tool for large-scale analyses of running gait. Pressure insoles such as the Runalyser provide valuable information for researchers, clinicians, podiatrists, athletes and coaches, and can provide real-time feedback in the athlete's habitual setting to help improve performance and prevent injury.

\section{Acknowledgments}

The present study was financially supported by the National Research Fund, Luxembourg (AFR Robert Mann: ref. 1102562). Thanks goes to Dr Marc Hoppenbrauwer of TNO, Eindhoven, The Netherlands for his technical support, the research team of the Physiology and Biomechanics of Locomotion Unit, Université Catholique de Louvain, Belgium for the use of their instrumented treadmill and to the study participants for their valuable contribution.

\section{Conflict of interest statement}

None to declare.

\section{References}

[1] Lieberman DE, Venkadesan M, Werbel WA, Daoud AI, D’Andrea S, Davis IS, et al. Foot strike patterns and collision forces in habitually barefoot versus shod runners. Nature 2010;463:531-6.

[2] Altman AR, Davis IS. Barefoot running: biomechanics and implications for running injuries. Current Sports Medicine Reports 2012;11(5):244-50.

[3] Lieberman DE. What we can learn about running from barefoot running: an evolutionary medical perspective. Exercise and Sport Sciences Reviews 2012;40(2):63-72.

[4] Jenkins DW, Cauthon DJ. Barefoot running claims and controversies: a review of the literature. Journal of the American Podiatric Medical Association 2011;101(3):231-46

[5] Squadrone R, Gallozzi C. Biomechanical and physiological comparison of barefoot and two shod conditions in experienced barefoot runners. Journal of Sports Medicine and Physical Fitness 2009;49(1):6-13.

[6] Cavanagh PR, Lafortune MA. Ground reaction forces in distance running. Journal of Biomechanics 1980;13(5):397-406.

[7] Altman AR, Davis IS. A kinematic method for footstrike pattern detection in barefoot and shod runners. Gait \& Posture 2012;35(2):298-300.

[8] Forner Cordero A, Koopman HJFM, van der Helm FCT. Use of pressure insoles to calculate the complete ground reaction forces. Journal of Biomechanics 2004;37(9):1427-32

[9] Savelberg HH, de Lange AL. novel Award Third Prize Paper. Assessment of the horizontal, fore-aft component of the ground reaction force from insole pressure patterns by using artificial neural networks. Clinical Biomechanics (Bristol Avon) 1999;14(8):585-92.

[10] Divert C, Mornieux G, Baur H, Mayer F, Belli A. Mechanical comparison of barefoot and shod running. International Journal of Sports Medicine 2005;26(7):593-8.

[11] Rosenbaum D, Becker HP. Plantar pressure distribution measurements. Technical background and clinical applications. Foot and Ankle Surgery 1997;3(1):1-14.

[12] Hennig EM, Milani TL. In-shoe pressure distribution for running in various types of footwear. Journal of Applied Biomechanics 1995;11(3):299-310.

[13] Larson P, Higgins E, Kaminski J, Decker T, Preble J, Lyons D, et al. Foot strike patterns of recreational and sub-elite runners in a long-distance road race. Journal of Sports Sciences 2011;29(15):1665-73.

[14] Hasegawa H, Yamauchi T, Kraemer WJ. Foot strike patterns of runners at the 15-km point during an elite-level half marathon. Journal of Strength \& Conditioning Research 2007;21(3):888-93.

[15] Hayes P, Caplan N. Foot strike patterns and ground contact times during highcalibre middle-distance races. Journal of Sports Sciences 2012;30(12):127583.

[16] Dierick F, Penta M, Renaut D, Detrembleur C. A force measuring treadmill in clinical gait analysis. Gait \& Posture 2004;20(3):299-303.

[17] Bland JM, Altman DG. Statistical methods for assessing agreement between two methods of clinical measurement. Lancet 1986;1(8476):307-10.

[18] Weir JP. Quantifying test-retest reliability using the intraclass correlation coefficient and the SEM. Journal of Strength \& Conditioning Research 2005;19(1):231-40.

[19] Barnett S, Cunningham JL, West S. A comparison of vertical force and temporal parameters produced by an in-shoe pressure measuring system and a force platform. Clinical Biomechanics (Bristol Avon) 2000;15(10):781-5.

[20] De Wit B, De Clercq D, Aerts P. Biomechanical analysis of the stance phase during barefoot and shod running. Journal of Biomechanics 2000;33(3):26978.

[21] Diebal AR, Gregory R, Alitz C, Gerber JP. Forefoot running improves pain and disability associated with chronic exertional compartment syndrome. American Journal of Sports Medicine 2012;40(5):1060-7.

[22] Kluitenberg B, Bredeweg SW, Zijlstra S, Zijlstra W, Buist I. Comparison of vertical ground reaction forces during overground and treadmill running. A validation study. BMC Musculoskeletal Disorders 2012;13:235. 